\title{
Clausewitz and the Gestalt of War
}

\author{
JOBBÁGy Zoltán
}

\begin{abstract}
War features unpredictability, incompleteness and instability. It is composed of a com-plex web of interconnected constituents in which friction poses a serious challenge. Clausewitz regarded war an integrated and holistic activity with having one gestalt as a functional unit. The term gestalt comes from German and stands for shape. It refers to the concept of wholeness with properties that cannot be summed up by their parts and do not equal a simple summation. Unpredictability helps us see war as a phenomenon that cannot be compounded from the actions of the constituent parts. War can be described with a certain precision, but this precision is not necessarily relevant to the parts. The gestalt of war accords with the observation that war does not always allow for logical, direct and traceable connections between causes and effects.
\end{abstract}

The aim of this article is to examine the problem of unpredictability, incompleteness and instability in war, and to detail the consequences that follow from these attributes. Simply put, the essence of causality can be described best by a series of deductive if/then statements that stand for linear connections in which a particular cause results in a particular effect. Clausewitz warned that in war "there is a gap between principles and actual events that cannot always be bridged by a succession of logical deductions." He also made clear that war is composed of a complex web of in- terconnected constituents in which friction poses a serious challenge. The consequence is circular causation in which causes and effects are connected via feedback loops. There is always a chance for escalation as tiny differences between causes can lead to completely different effects over time. This indicates the impossibility to predict future time paths in the form of desired effects. ${ }^{2}$

\section{Jomini and the Scientific Narrative}

Approaching war in terms of causality means that we regard it as an analytically solvable, hence scientific phenomenon that allows for prediction in the form of causal statements. However, ac- cording to Clausewitz war's proverbial friction stands for disguised correlations rather than de- tectable causal relations. A causal focus bears the risk of disregarding the difference between cor- relation and causation. ${ }^{3}$ Addressing war in a causal way inadequately captures its dynamic nature. Jomini desperately tried to establish a scientific theory of war, a good one and a half centuries ago. He provided his readers with a meaningful set of standardised scientific methods. He developed four maxims for the fundamental principle of war, but failed to make that very principle explicit. He provided the reader with eight rules for selecting tactical positions, twelve orders of battle, thir- teen points for fighting battles, five directions for an attack by main force, three rules for pursuit, eighteen points for the movements of armies, and nineteen rules for the use of the artillery. ${ }^{4}$

1 CLAuSEWITZ (1993) p. 125.

2 STACEY (1996); WESLEy (2002)

3 CHrISTENSEN-rAyNOr (2003)

4 KuHN (1962); JOMINI (1992)

Time has mostly parodied and ridiculed his attempt to provide a scientific categorisation of war. Unlike the appreciation and influence he possessed before World War I, contemporary readers often find his work to be narrow, simplistic, occasionally boring and overtly superficial. Analysing only a small number of selected variables has a limited potential that yields a restricted set of op- tions. Putting those options through the filter of various analyses and evaluations further narrows our blinders and does not address important issues such as clarity, rigour and utility for real-world application. Thus by looking at Jomini we have the impression that employing analytic principles of scientific inquiry can at best address war fought on paper but not real war fought with blood and guts. Jomini's rigid, dogmatic and prescriptive thinkingthas relevance only for the former and even then with a strong limitation. ${ }^{5}$

Forced scientific principles based on direct causality and deduction, analytical rationality and categorisation fail to address much of war's frictional mechanism. Scientific principles might be helpful in describing war, but its dynamics cannot be analysed on strict scientific principles only. The scientific narrative used by Jomini has its roots in the failed geometrical and mathematical schools of European military thinking of the outgoing $18^{\text {th }}$ century. Any approach of this kind bears the danger of taking the art out of warfare by inserting more science at the same time. ${ }^{6}$

\section{Causal Focus of Science}

In order to explain the recurring popularity of applying scientific principles to war it is important to take a close look at the way science normally develops. According to Kuhn, the early stages of any science, for which he used the term normal 
science, display a vast array of descriptions and interpretations that largely disappear when one of the competing schools triumphs. Scientific inquiry is a causal process that works toward homogenisation and ends with the acceptance of a certain paradigm. It proceeds by improving paradigms in the form of an infinite and spiralling determining-matching-articulating cycle. First it determines significant facts of reality at hand, then it matches significant facts with theory, and in the last stage it articulates the theory based on significant facts. This process implies that paradigms are objects for further articulation and spec- ifications should new conditions arise. They are built on a few problems at hand to be solved and their success depends largely on the ability to force those problems into a preformed and inflexible box. Paradigms do not call for new sorts of phenomena since those that do not fit into them are often ignored and normally left aside. The result of this causal approach is a drastically restricted and narrow focus, which is both the driving force behind any scientific inquiry and the enabler to predict factual information of intrinsic and substantial value. ${ }^{7}$

Paradigms indicate that scientific endeavour is highly cumulative in its result. The steady ex- tension of its scope and the ever-increasing precision of the knowledge gained result in science not aiming at factual or theoretical novelties, and in the case of success it finds none. As time passes not all existing theories of a scientific field support a given paradigm. Paradigms do change and those changes are normally accompanied by many speculative, roughly articulated and ad-hoc modifications. Paradigms can tolerate crises and accommodate tensions to a certain degree, but due to their causal focus scientists normally try to avoid anomalies and conflicts with existing paradigms. Consequently, science proceeds through the change of paradigms, which explains why scientists do not see something as something else, they just simply see it. As a result of the causal

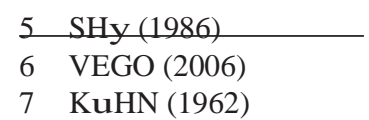

focus of paradigms science proceeds towards a narrowing and ever increasing subdivision of its field of inquiry. It is exactly this causal focus that separates scientific activities from artistic activ- ities. Clausewitz indicated that scientific endeavour with all its paradigms, methods and standards seeking causality, does not have much relevance for war. Friction does not allow for a narrow focus aimed at exploiting causal relationships in war. ${ }^{8}$

The most striking character of science is its ever-increasing specialisation, which evolves through the prolonged utilization of the scientific method of inquiry. In terms of scope and con- cern, the successive stages point towards an increase in detail and refinement. This means that while science can grow in depth, it may not grow equally in breadth. Facts of scientific inquiry always reflect the crude facts of nature and translate these facts into another and more convenient language. The properties of the raw material on which the inquiry focuses always limit scientific freedom. This limitation, also in terms of causality, indicates that the border between rough and scientific facts can never be precisely drawn. ${ }^{9}$

Due to such imprecise borders, any given law of science is always approximate, probable, and incomplete. Although it can be replaced by other, closer and more probable laws ad infinitum, it will always be an approximation differing as little as chosen "from exactitude and the probability from certitude." 10 Laws and paradigms are useful tools for scientific inquiry, but they are by defi- nition imperfect and provisional. The often praised objectivity of science is nothing more than a provisional, crumbling and crude image. It indicates that even natural science can never be true, only convenient. ${ }^{11}$

\section{Unpredictability as Gestalt}

The causal focus of natural science does not indicate that paradigms can stay unchanged. They do change from time to time, which induces re-examination and re-education of the existing world view. This painful and controversial process is normally accompanied by the emergence of a novel gestalt. The term comes from German and stands for shape that refers to the concept of wholeness. A gestalt stands for a functional unit with properties that cannot be summed up by their parts. Thus a gestalt does not equal a simple summation. ${ }^{12}$

Clausewitz did not attempt to provide a scientific image of war and did not come up with any paradigm for a phenomenon that "appear[s] to defy a "scientific" approach."13 Clausewitz regarded war an integrated and holistic activity with one common denominator, a functional unit that forms a recurrent pattern in his work. unpredictability can be seen as Clausewitz's gestalt for war. unpre- dictability is manifest in friction and best expresses his message that war is an 1 extended event that cannot be properly described as the exact sum of smaller and independent events. unpredictability as gestalt displays war as a human phenomenon, which poses problems often falling outside the reach of scientific inquiry, paradigms and causal explanations. Unpredictability helps us see war as a functional whole that cannot be compounded from the action of its constituent parts. unpre- dictability can be described with a certain precision, but this precision is not necessarily relevant to the parts as war does not allow for logical, direct and traceable connections between causes and

8 KuHN (1962); CLAuSEWITZ (1993)

9 KuHN (1962); POINCAré (1982)

10 POINCAré (1982) p. 341.

11 POINCAré (1982)

12 KuHN (1962); GOVE (1981) 
effects. unpredictability comes as a result of mutually determined parts of an interactive process that cannot be adequately described by the sum of causal relationships. It indicates that causes and effects are often the result of hidden, intrinsic

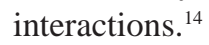

unpredictability comes as the result of terror, disequilibrium, and non-linearity created by two opposing groups of intelligent human beings. Scientific paradigms stand for firm and reliable infor- mation regarding some basic assumptions in terms of causality. Unpredictability in contrast reflects that war always depends on a wide variety of factors that can either be known, unknown but know- able, or unknown and unknowable. unpredictability is responsible for the gap between information known and information desired to be known, which in the case of science can normally be filled by scientific inquiry and endeavour. $^{15}$

Science and its supporting paradigms always assume that there are clear and definite answers to clear and definite questions. The driving force is a causal assumption that information known and information to be known can eventually overlap. In war there is no such overlap as the only certainty is that war waged differs from the war expected to wage. Clausewitz pointed out that war often seems to be the difference between plans and events, fiction and reality. The most striking difference between war and science is that the research of the former can mostly be defined by a lack of any significant progress. This explains why it is still possible to refer to a theorist who lived nearly two centuries ago. Many theories of war display various mutually inconsistent propositions and findings that exist side-by-side and do not allow for the establishment of any sort of scientific paradigm. This anomaly is mostly of a systemic nature, and is manifest in the impossibility of applying the methods of scientific inquiry to war. War is a context-dependent cultural and social system consisting of a network of components that often act in parallel. The result is that every- thing moves, as nothing is stationary. ${ }^{16}$

\section{Sources of Unpredictability}

unpredictability as proposed gestalt of war might be bewildering at first. During most of our life we are socialised to see the known, and are rarely prepared to learn about the unknown. Conse- quently, the known is pressed on our mind from the outset and the unknown is regarded mostly as irrelevant. We conveniently move along a narrow path of knowledge and think that more is known than actually is. As time passes we are confident that many unknown things usually become known. However, the unpredictability of war indicates that beyond the contours of the unknown there is a vast array of inherently unknowable phenomena. Science reflects the natural world by focusing on the known and the unknown, but mostly leaves the unknowable out of its scope. It is a correct, but artificial reflection of the natural world in which paradigms provide convenient tools that are always simpler and more controllable than the natural and original. Given that war is waged by complex and idiosyncratic humans, any attempt to separate the known, the unknown and the unknowable is thus impossible. ${ }^{17}$

unpredictability stands for various possibilities in war. Clausewitz emphasised the impossibility of making predictions on the outcome in terms of causal statements. It is not surprising that for critiques On War is a theoretical mess, since it offers many and often contradicting views regarding the mech-

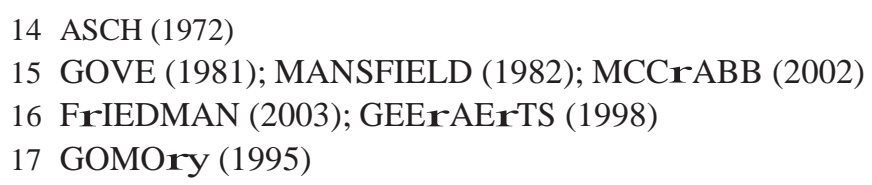

anism of war. Although Clausewitz's reasoning was limited by the state of science and its vocabulary of his age, as a compelling classic of Western military thinking, he was among the first who explicitly addressed war's complex and non-linear character. He emphasised that the conduct of war is not an analytical process, but one that always changes in an unpredictable way. Confronted with the unknow- able and having no better toolset than the scientific vocabulary of the early $19^{\text {th }}$ century explains why he introduced the idea of friction, which is an essentially mechanical, hence a scientific term. ${ }^{18}$

Clausewitzperceived war as a phenomenon involving a large number of interactive and com- peting factors that display a messy interplay between order and disorder, predictability and un- predictability. For him, waging war was a non-linear and dynamic process in which the inherent complexities and probabilities could not be seen as isolated phenomena. Beyerchen identified three sources of unpredictability such as interaction, friction, and chance. unpredictability from inter- action emphasises war as an interactive process between intelligent and adaptable human beings. Actions in war do not produce simple reactions, but dynamic interactions, and any attempt to anticipate the enemy's move runs into considerable difficulty. Interactions allow only for vague assumptions in the form of generalisations based on qualitative theorising. War is a structurally unstable phenomenon, which means that participants must always expect disproportional effects and unpredictable situations. Friction as the second source of unpredictability has already been detailed. It is the sort of resistance that stands for the feedback effects responsible for constant novelty, and the fact that things in war never go as planned. Friction is the noise in the system of war and expresses how information distortion and overload can produce uncertainty regarding the actual state of affairs. Both resistance and noise emphasise that it is not possible to calculate in 
Jobbágy Zoltán: Clausewitz and the gestalt of War

advance what cause results in what effect. It is equally impossible to predict which effect will turn out to be critical and decisive. unpredictability based on chance means that most of the factors on which actions are based are obscured and distorted in war. Chance has three sources from which it stems, such as statistically random phenomena, amplification of micro-causes, and the result of an- alytical blinders. All refer to the role of probability in calculations due to the enormous amount of variables. The result is that small causes can generate disproportionate effects and there will always be the possibility that the result of any given action can defy the odds. The precision of available information regarding causes and their effects is always limited and attempts to reconstruct causal relationships will always face the lack of precise and accurate information. ${ }^{19}$

Clausewitz emphasised that human intuition is guided by linear conceptions, which are of analytical convenience rather than real-world relevance. unpredictability as gestalt indicates that attempts to generate principles for the conduct of war and discern clear causality is a desirable, but an unattainable goal. ${ }^{20}$

\section{Chaotic Nature of War}

War is a phenomenon composed of a multitude of connected parts and according to Clausewitz every act in war has consequences, which could be either intended and immediately obvious, or unintended and delayed. Although he knew that war displays cause-and-effect relationships, he equally argued that war's frictional mechanism renders it largely impossible for most attempts to take full advantage of direct causality. ${ }^{21}$

18 BEyErCHEN (2005); FLEMING (2004)

19 BEyErCHEN (2005)

20 BEyErCHEN (2005)

21 BEyErCHEN (2005)

Whereas he invented friction to describe war's unpredictability, we can refer to the recent concept of chaos that offers a more detailed insight into the mechanism of war. Strictly speaking chaos is a mathematical concept that does not mean anarchy or confusion. It describes disorder that arises from non-random causes. Chaos is used to describe a range of irregular behaviours in which seemingly random occurrences can be depicted by entirely deterministic and often very simple equations. Chaos occurs in nearly all aspects of military affairs and stems from the presence of feedback. The behaviour of a chaotic system is non-periodic and apparently random, which means that the system's response is recurrent, but no longer predictable. The inability to make long-term predictions in chaotic systems is not due to the lack of data, but an immediate consequence of the non-linear rules that govern its behaviour. Deterministic chaos can best be described as irregular or random appearances of nonlinear dynamic systems, in which dynamic laws determine the time evolution of the system based on its history. The necessary ingredients for a system to be labelled as chaotic are, among others, non-linearity, nonperiodicity, sensitivity to initial conditions, and mixing. Chaos' biggest implication for war is that in non-linear systems we must always expect instability in the form of novelty. ${ }^{22}$

Clausewitz suggested that war is chaotic and there is no way to predict the effect of the actions of the participants with any great certainty. Historical evidence indicates that predictability and control are already lost at the threshold separating war and peace. In a chaotic system small per- turbations of initial conditions can lead to unforeseen changes. War's unpredictability is as much manifest in creating structures, as it is in tearing them apart. The creation and dissolution of order go hand in glove and defy most explanations based on deductive causal models, which is an im- portant characteristic of scientific research. ${ }^{23}$

Although chaos is a deterministic mathematical concept that does not mean randomness, in English parlance it is understood heuristically, and synonymous with chasm, gulf or abyss. Chaos includes chance, which is subject to no law and displays no signs of uniformity. It is not a distinct or an orderly form, but precedes the creation of order. In war military operations often display a state of confusion including complete disorder, lack of sequence, organization, and any sign of predictability. Chaos in war seems to be for many "a confused mass or agglomerate of matters or heterogeneous items that are hard to distinguish, isolate or interpret." 24

\section{War, Chaos and Determinism}

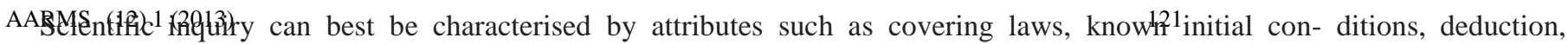
prediction and explanations. The result is deductive-nomological models capa- ble of connecting causes and their effects each occurring as contiguous instants at their own place and time. Mathematically chaotic systems are deterministic and governed by laws that indicate intimacy between causes and their effects, since only their sensitivity to initial conditions qual- ifies them as chaotic. In war, attempts to connect causes and effects run against war's frictional mechanism lacking such intimacy. Despite similarities in terms of chaos, war probably cannot be regarded as a chaotic system in strictly mathematical terms. Although it displays particular factors and events coalescing in various proportions to realise their end, war is far more complex than any sophisticated mathematical model. ${ }^{25}$ 
All these factors together with the human tendency to gauge decisions by relatively external events indicate the impossibility of comprehending all variables in war. The result is that war cannot be regarded as a closed and isolated phenomenon. The greater the temporal and spatial difference between initial conditions, the bigger the inaccuracy with which those conditions can become known. Temporal and spatial factors always diminish the accuracy of any deductive and nomological explanation, which can only cover events and their immediate consequences. War displays tangled and intricate relationships and as various temporal and spatial limitations indicate, causal relationships in war are never fully contiguous or fully point-like. ${ }^{26}$

Any attempt to detect causality must contend with an emergent novelty. unpredictability as ge- stalt of war does not allow for any separation into parts to be studied individually, but is composed of so many components and elements that identifying causal subordinations to newly emerging pro- cesses can be very difficult, if not impossible. Although certain aspects of emergent properties might allow for detecting causal relationships, other aspects possess characteristics of their own that cannot be determined in terms of causality. Thus in the case of analytical rationality and categorisation we face a general methodological problem. Attempts to identify the components of a given system and the dimensions according to which they are arranged can only be done incompletely. Open and dynamic systems evolve over time. Any identification process can be considered adequate only, if we are able to enumerate all the unfilled positions and the strains they create. This however, is again supplicated to a novelty we cannot anticipate as such systems do not exhibit mathematically repre- sentable temporal series of behaviour. Consequently, the system is unquantifiable in terms of causal relationships and does not permit accurate prediction regarding its future states. ${ }^{27}$

\section{War as Natural Form}

The issue of determinism/indeterminism in war is closely related to human free will. An irregular- ity understood heuristically is not generally incompatible with determinism, except when it has no determining conditions for its occurrences. ${ }^{28}$

We often might not precisely know the conditions for the occurrence of many chaotic events, but are basically confident regarding those conditions. This confidence explains why it is possible to es- tablish relationships between statistical properties of events, and why we are less successful in doing the same for individual events and their properties. Applying various statistical variables expresses our ability to consider the statistical properties of the elements accompanying the events. The ques- tion of whether events occur in an absolutely heuristic or deterministic fashion is not an issue that has significant importance as real life is compatible with both. Thus the question of whether structures are heuristic or deterministic in war is basically nothing more than a subject of inconclusive controversy, since both indicate unpredictability. Heuristic and deterministic structures refer to natural forms that stand for occurrences and phenomena we can perceive. They are isomorphic structures across the fields of human inquiry such as biological cells, economic societies, the population of organisms, and in our case - war. Natural forms can be understood either as a natural complex or a natural system. Although both refer to the same, they possess different attributes. Whereas a natural complex displays purposeful forms and organic interactions among the constituents, a natural system displays chaotic forms and topographic interactions among the components. ${ }^{29}$

26 POOL (1989)

27 EMEry (1974)

28 LOrENZ (1993)

Thus any given natural form can be examined either as a natural complex or as a natural system. Although both constructs stand for unpredictability, the difference comes from subjective interest. Natural complex is a form composed of constituents, which are non-separable from each other. Every attempt to divide or dissect a natural complex obviously changes its identity. Due to the organised division of labour within such a complex, one constituent's particular function comple- ments the function of the other constituents organically. The unpredictability of a natural complex arises from non-determinism, as it reacts differently to the same stimulus. Natural system is com- posed of constituents that are separate, but not independent from each other, which indicates that the components act as external and arbitrary impetuses. They are separate, but have a

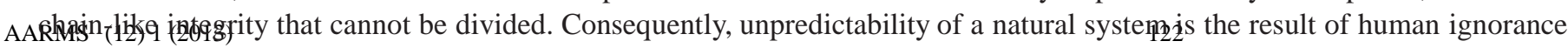
regarding all the factors at play and we face determinism in which topographic interactions involve efficient causation. ${ }^{30}$

War as a natural form can be regarded both as a heuristic and deterministic phenomenon in which the difference does not come as a result of the underlying attributes, but as of respective in- quiry. War as a natural form indicates similarities with systems, such as the weather or a rain forest, which might be heuristic real-world phenomena, but can nevertheless be modelled and explained to a given degree by deterministically chaotic mathematical models.

\section{Incompleteness and Instability}

Due to the presence of chaos in war, the history of warfare is replete with examples in which dra- matic consequences resulted from minor actions, or that identical actions have resulted in different outcomes. War as a distinct and specific form of social interaction does not always display a direct relationship between causes and effects. The obvious similarity between a chaotic 
abstract mathemat- ical model and a chaotic social and cultural phenomenon such as war allows for an extended exam- ination of unpredictability. Chaotic structures are vulnerable to dissolution, and the higher the number of actors and longer the time-scale of prediction, the greater the problem of accuracy. regardless of whether chaos is seen as a deterministic or heuristic phenomenon, it indicates that in war the general push for stability is nothing more than illusion. ${ }^{31}$

War is full of dispersed, diffuse, intermittent and irregular processes that stand for fluid and dysphasic movements constantly eroding attempts to achieve symmetry and order. Consequent- ly, war stands for a constant interplay between fractalisation and the drive for homogeneity. ${ }^{32}$

War as a natural form also reminds us that any outcome reflects the complex interactions of the constituents in which unpredictability is at best the "combined effect of friction, disruption, and lethality of unit behaviour". ${ }^{33}$

regardless of how we name the aggregate results, war does not provide for consistency and completeness either. Whereas consistency refers to the lack of contradictions, completeness ex- presses the ability to provide for proofs of all true statements. Even if war provided for such attri- butes and could be described entirely in mathematical formulas, Gödel proved that it is not possible to reach consistency and completeness. According to him all formal mathematical systems, despite the fact that they display completeness and consistency, are inherently incomplete. They might be true, but cannot be proved despite the abundance of existing axioms and rules of inference. Gödel

30 KHALU (1990); BuCHLEr (1966)

31 MANN (1992); PEATLAND (1993)

32 SAPErSTEIN (1995); BEAuMONT (1994); NICHOLLS-TAGArEV (1994); WEEKS (2003)

33 CrAMEr (1993); PFAFF (2000); HErMAN (1999) p. 87.

understood formalisation as achieving consistency and completeness, in which axioms and rules are tools applicable to all mathematical questions in expressible formulas. However, he concluded that consistency and completeness can never be reached even in formal mathematical systems, as there would always be simple problems that cannot be decided from axioms. Since problems of this kind appear in a very extensive class of formally expressible systems, he concluded that ev- ery formal system must contain propositions that cannot be decided. In other words, there would always be propositions that cannot be proved or disproved. Gödel's theorem indicates that there are always propositions that assert their own improvability. Consequently, even formal systems in which the class of axioms and rules of inference can be recursively defined display undecidable propositions. Similar to a complex social phenomenon such as war even formal mathematical sys- tems are incomplete and display logical inconsistency. ${ }^{34}$

\section{Structural Variance and Non-Monotonicity}

Gödel's incompleteness theorem also explains why computer-based simulations of war are essen- tially unstable and display inconsistency between input and output. Computer simulations are ex- cellent examples that even if there are definable deterministic relationships within a given system that can be formalised mathematically, we must always expect occurrences that cannot be proved or disproved in terms of causality. ${ }^{35}$

Despite attempts to comprehend war in terms of causality we always face inconsistency and incompleteness. Even simpler settings that attempt to model it show non-linear attributes and signs of instability. The Lanchester equations were the first combat model that attempted to estimate war mathematically in terms of casualty rates. Lanchester wanted to catch the essence of loss ratios in combat based on a pair of coupled differentials. From a contemporary point of view the equations seem very crude and clumsy tools. Growing computing power in the second half of the $20^{\text {th }}$ centu- ry has enabled analysts to model increasingly more aspects of war's complex features. However, the result of this development was that the relatively simple model instability of the Lanchester equation has been replaced by other instability yielding more divergent and unexpected results. ${ }^{36}$

The term structural variance was the first attempt to express the occasional and seemingly erratic behaviour that came from a strictly deterministic mechanism of the models employed. An- other attempt to describe model outputs, which were

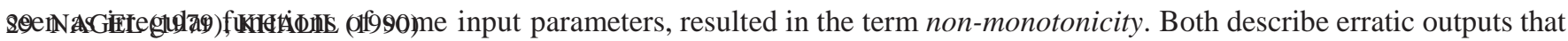
were regarded mostly as the analysts' faults. Although first efforts were aimed at finding reduction techniques for these anomalies later jit was found that in the case of complex simulations, even infinitely small factors such as computer rounding errors, can become the source of instability. It was concluded that dynamic instability appears to be an inherent feature of complex simulations. This conclusion however, allows for a much broader generalisation. If deterministic combat models, based on high- ly controlled conditions can display irregular outputs, then real wars in which the signs of determinism are less clear may be destined to do so. real war is always more complex than any model can ever become. Therefore if relatively simple computer models can show signs of instability then "the instability of the corresponding reality is certainly implied."This however, allows only for a very low practical ceiling for applying scientific principles for war. ${ }^{37}$ 


\section{Conclusion}

Clausewitz wanted to "iron out a good many kinks in the minds of strategists and statesmen [and] to show what the whole thing is about and what the real problems are that have to be taken into account in actual warfare." ${ }^{38}$ In a similar, but more limited fashion it was our intention to examine certain aspects of war and display it as a phenomenon that allows for causal explanations only with clear limitations.

unpredictability as gestalt indicates that any sober theory must take into account that waging war is an act that has always been more than linking ends with means. A scientific approach to war represents deductive reductionism and causal laws attempting to predict certain effects. The sup- porting assumption is that war displays order and equilibrium, the possibility for rational choice, and the ability to steer and control events. War however, contains variety and novelty in which cer- tain properties remain unknowable to the human mind. War can be described in general terms using causal relationships, but effects that go beyond the immediate spatial and temporal levels cannot be predicted with any accuracy. In war everything is interrelated and all we can attain is nothing more than a temporary and partial interpretation.

unpredictability as gestalt reminds us that instead of focusing on certain desired effects, we should embrace its friction and respond consistently to its unpredictable occurrences. War cannot be waged based on single and prescriptive models, but requires that we evolve rapidly in order to handle dynamic and changing situations. Thus we must be satisfied with understanding certain general features in terms of correlation, rather than attempting to discover a mechanism that links causes with effects directly. War is full of emerging opportunities that can only help explain quali- tative behaviour, but never accurately predict futures in terms of effects.

unpredictability as gestalt reflects that scientific principles such as deduction, analytical rationali- ty and systemic thinking have limitations for war. War might display direct causality, but assumptions that rest on equilibrium and a constant environment make up only a small fraction of its bewildering nature. However, at first glance a scientific approach might appear to be weighty both in scope and insight as it draws on a diverse array to generate hypotheses about war. This eclecticism is admirable, but often indicates inconsistency and a vocabulary that has no sound foundation. Even deductive thinking and analytical rationality do not make it possible to distinguish sufficiently among various alternatives nor can satisfyingly explain the preference for certain selected factors.

unpredictability as gestalt warns us that blind adherence to predefined objectives can result in mounting costs both in terms of money and men. Accepting surprise, making moves, observing the results and continuing with the ones that seem to work are inherent features of war. Any conceptu- alisation of war can be scarcely more than an attempt to grasp a continuously shifting process. War happens on a continuum and it is understandable that focusing only on certain factors is necessary for analytical reasons. However, narrow conceptualisations that do not provide for compelling explanations and instead of examining variations in terms of their appearance, emphasize only apparent similarities. This appears to be plausible at first glance, but a closer examination reveals it to be problematic. It obscures truly intriguing differences that might theoretically belie the notion that wars and military operations should be analysed as a uniform class.

unpredictability as gestalt highlights that although it is always helpful to discern certain uni- versals that can guide our actions, turning those universals into fixed laws and values with the hope to detect causal relationships, is mostly impossible. War is a context-dependent human phe-

38 CLAuSEWITZ (1993) p. 78.

nomenon that does not provide for blueprints to act on. It moves back and forth from stability to chaos that occurs simultaneously across its various levels. Consequently, success in war demands the ability to learn from actual experience, rather than the ability to formulate action based on past experience. Waging war is as much a science as an art and that must be taken into account in every conceptualisation.

The completion of this study was done within the framework of TÁMOP-4.2.1.B-11/2/KMR-2011-

0001 “Critical Infrastructure Defence Research" program: “Civilian-Military Partnership" sub-program: "Development of Human Defence, Peace Operation and Crisis Management Pro- cesses” major research area.

\section{References}

ASCH, Solomon E. (1972): Gestalt Theory. In SILLS, David 1. (ed.): International Encyclopedia of the Social Sciences, Volume 16, New york Macmillan \& The Free Press, pp. 158-174

BEAuMONT, roger (1994): War, Chaos, and History, Praeger Publishers.

BEyErCHEN, Alan D.: Clausewitz, Nonlinearity and the Unpredictability of War. www.clausewitz.com/ CWZHOME/Beyerchen/CWZandNonlinearity.htm (02.08.2005.)

BuCHLEr, Justus (1966): Metaphysics of Natural Complexes, Columbia university Press. CHrISTENSEN, Clayton M. - rAyNOr,

Michael E. (2003): Why Hard-Nosed Executives Should Care 
Jobbágy Zoltán: Clausewitz and the gestalt of War About Management Theory, Harvard Business review, September 2003, pp. 67-74

CLAuSEWITZ, Carl von (1993): On War, Everyman's Library.

COVENEy, Peter - HIGHFIELD, roger (1995): Frontiers of Complexity, The Search for Order in a Chaotic World, Faber and Faber.

CrAMEr, Friedrich (1993): Chaos and Order, The Complex Structure of Living Systems, VCH Verlags- gesellschaft.

DurHAM, Susan E. (Maj.) (1997): Chaos Theory for the Practical Military Mind, Air Command and Staff College, March 1997

EMEry, Frederick E. (1974): Methodological Premises of Social Forecasting, in: Annals of the American Academy of Political and Social Science, Volume 412, The Information revolution, March 1974, pp. 97-115 https://doi.org/10.1177/000271627441200110

FLEMING, Bruce (2004): Can Reading Clausewitz Save Us from Future Mistakes? Parameters, Spring 2004, p. $62-76$

FrIEDMAN, George (2003): The Unpredictability of War and Force Structure, The STrATFOr Weekly, 29 September 2003. www.vialardi.org/IrAQ/unpredictability _of_war.html (12.08.2005) GEErAErTS, Gustaaf (1998): Non-

Linearity, Chaos and the Predictability of War, Pole Paper, Volume 4,

Number 1, January 1998. www.poli.vub.ac.be/publi/pole-papers/pole0401.htm (02.08.2005.) GöDEL, Kurt (1962): On Formally

Undecidable Propositions of Principia Mathematical and Related Systems, Basic Books.

GOMOry, ralph E. (1995): The Known, the Unknown and the Unknowable, essay, Scientific American, June 1995, p. 88. https://doi.org/10.1038/scientificamerican0695-120

GOVE, Philip B. (ed. i. ch.) (1981): Webster's Third New International Dictionary of the English Language, unabridged, Merriam-Webster Inc.

HErMAN, Mark (1998): Entropy-Based Warfare: Modelling the Revolution in Military Affairs, Joint Forces Quarterly, Autumn/Winter 1998-99, pp. 85-90.

ILACHINSKI, Andrew (1996a): Land Warfare and Complexity, Part I: Mathematical Background and Technical Sourcebook, Center for Naval Analyses, CIM 461, July 1996.

ILACHINSKI, Andrew (1996b): Land Warfare and Complexity, Part II: An Assessment of the Applicabil- ity of Nonlinear Dynamics and Complex Systems Theory to the Study of Land Warfare (U ), Center for Naval Analyses, CrM 96-68, July 1996.

JAMES, Glenn E. (1996): Chaos Theory, The Essentials for Military Applications, The Newport Papers, Naval War College, October 1996

JOMINI, Baron Antoine Henri de (1992): The Art of War, Greenhill Books, London, Stackpole Books, Pennsylvania, 1992

KHALIL, Elias L. (1990): Natural Complex vs. Natural System, Journal of Social and Biological Struc- tures, Volume 13, Number 1, 1990, pp. 11-31 https://doi.org/10.1016/0140-1750(90)90031-Z

KLINGEr, Janeen (2006): The Social Science of Carl von Clausewitz, Parameters, Spring 2006, pp. 79-89

KuHN, Thomas S. (1962): The Structure of Scientific Revolutions, International Encyclopaedias of unified Science, Foundations of the Unity of Science, Volume 2, Number 2, 1962

KuruC, Anton (2003): The Relevance of Chaos Theory to Operations, Australian Defence Force Jour- nal, Number 162, September/October 2003, pp. 4-16

LOrENZ, Edward N. (1993): The Essence of Chaos, uCL Press.

MANN, Steven r. (1992): Chaos Theory and Strategic Thought, Parameters, Autumn 1992, pp. 54-68

MANSFIELD, Sue (1982): The Gestalts of War, An Inquiry into Its Origins and Meanings as a Social Institution, The Dial Press.

MCCrABB, Maris Dr.: Uncertainty, Expeditionary Air Force and Effects-Based Operations, Air Force research Laboratory, 2002b, pp. 7-8. www.eps.gov/EPSdata/uSAF/Synopses /1142/reference-Num- ber-PrDA-00-06IKFPA/uncertaintyandoperationalart.doc (23.04.2003)

NAGEL, Ernest (1979): The Structure of Science, Problems in the Logic of Scientific Explanation, Hack- ett Publishing Company.

NICHOLLS, David (Maj.) - TAGArEV, Todor (Maj.) (1994): What Does Chaos Theory Mean for War-fare?, Aerospace Power Journal, Fall 1994, www.airpower.maxwell.af.mil/airchronicles/apj/apj94/ nichols.html (10.12.2003.)

PEATLAND, Pat A. (Lt. Col.) (1993): Centre of Gravity Analysis and Chaos Theory, Air War College, Air university, April 1993.

PFAFF, Charles A. (Maj.) (2000): Chaos, Complexity and the Battlefield, Military review, July August 2000, pp. 83-86.

POINCAré, Henry (1913): The Foundations of Science, Science and Hypothesis, The Value of Science, Science and AARMS (12) 1 (20Mb)thod. The Science Press, New york and Garrison.

POOL, robert (1989): Chaos Theory: How Big an Advance? Science, 7 July 1989, pp. 26-28

rEISCH, George A. (1991): Chaos, History and Narrative, History and Theory, Winter 1991, pp. 1-20

SALMON, Wesley C. (2002): Causation. In: GALE, richard: Blackwell Guide to Metaphysics, Blackwell,.

SAPErSTEIN, Alvin M. (1984): Chaos - a model for the outbreak of war, Nature, 24 May 1984, pp. 303-305

SAPErSTEIN, Alvin M. (1991): The "Long Peace" - Result of a Bipolar Competitive World, Journal of Conflict Resolution, Volume 35, Number 1, March 1991, pp. 68-79

Saperstein, Alvin M. (1995): War and Chaos, American Scientist, November-December 1995, pp. 548-557

SHy, John (1986): Jomini. In PArET, Peter (ed.): Makers of Modern Strategy: From Machiavelli to the Nuclear Age. Princeton: Princeton university Press, 1986, pp. 164-184 https://doi.org/10.2307/j.ctv8xnhvw

SIDrAN, Ezra D. (2004): A Calculated Strategy: Readings directed towards the creation of a strategic artificial intelligence, readings for research, Spring 2004, pp. 11-13, www.cs.uiowa.edu/ dsidran/ 
readingsForresearch2.pdf (10.11.2005.)

SPEIGHT L. r. (2002): Lanchester's Equation And The Structure of the Operational Campaign: Between-Campaign Effects, Military Operations research, Volume 7, Number 2, 2002, pp. 15-33

SPEIGHT, L. r. (2003): 'Structural Variance' or 'Non-Monotonicity' Effects in Combat Models: A Review, Military Operations research, Volume 8, Number 1, 2003, pp. 17-33

STACEy, ralph D. (1996): Strategic Management \& Organisational Dynamics, Pitman Publishing. VEGO, Milan N. (2006): Effects-Based Operations: A Critique, Joint Force Quarterly, Issue 41, ${ }^{\text {nd }}$ Quarter 2006, pp. 51-57

WEEKS, Michael R. (Maj.) (2003): Chaos, Complexity and Conflict, Air \& Space Power Chronicles. www.airpower.maxwell.af.mil/airchronicles/cc/Weeks.html (22.05.2003.) 